\title{
The effects of pregnancy on the sexual life of Turkish women
}

\author{
Hasan Efe, ${ }^{1}$ Murat Bozkurt, ${ }^{2}$ Levent Sahin, ${ }^{2}$ Mehmet Fırat Mutlu, ${ }^{3}$ Murat Api, ${ }^{4}$ \\ Ahmet Çetin ${ }^{5}$
}

Keywords: Pregnancy, coitus, sexual behavior, libido, Turkey

\begin{abstract}
Aim: To investigate the effects of pregnancy on the sexual life of Turkish women

Materials and Methods: One thousand twenty six pregnant women were included in the study. The Libido Scoring System, which is a questionnaire consisting of four questions about the frequency of intercourse, the partner initiating the intercourse, orgasm and masturbation status of the pregnant women, was completed by all patients. Both prepregnancy and pregnancy sexuality was evaluated independently using this scale.
\end{abstract}

Results: The frequency of sexual intercourse during pregnancy significantly decreased from 3.07/week to 2.40/week $(p<0.05)$. The masturbation rate during pregnancy was significantly lower than the pre-pregnancy period $(3.6 \%$ vs $4.9 \%, p<0.001)$. The percentage of pregnant women who never had an orgasm was significantly higher compared to the pre-pregnant period ( $21.7 \%$ vs $10.8 \%$, $p<0.01)$. The rates of initiation of sexual intercourse in the pre-pregnancy period by men and by women were 94.5\% (970/1026) and 5.3\% (54/1026) respectively. In pregnancy period the rates of initiation of sexual intercourse by man and woman were $93.4 \%$ (904/968) and $6.6 \%$ (64/968) respectively $(p=0.0001)$. The mean libido scores during pregnancy were statistically lower than the prepregnancy period $(6.38 \pm 0.04$ vs $7.31 \pm 0.04$, $p<0.001)$.
Conclusion: Pregnancy has a negative effect on the sexual life of women, but more prospective studies are required to clarify the mechanisms.

\footnotetext{
${ }^{1}$ Department of Psychiatry, Faculty of Medicine, Istanbul University, Capa, Fatih, Istanbul, Turkey

${ }^{2}$ Department of Obstetrics and Gynecology, Kafkas University School of Medicine, Kars, Turkey

${ }^{3}$ Department of Obstetrics and Gynecology, Health Research System Hospital Ankara, Turkey

${ }^{4}$ Department of Obstetrics and Gynecology, Zeynep Kamil Maternity and Children's Hospital, Istanbul, Turkey

${ }^{5}$ Department of Obstetrics and Gynecology, Haseki Education and Research Hospital, Istanbul, Turkey
}

\section{Introduction}

The anatomical, physiological and emotional changes that occur during pregnancy impact a woman's whole life, including her sexuality. Physical discomfort, fear of fetal injury, dyspareunia, and decreased sexual desire may lead pregnant women to abstain from sexual intercourse; however, the restriction of sexual activity in a healthy pregnancy is unneccesary. ${ }^{1}$

Please cite this paper as: Efe H, Bozkurt M, Sahin L, Mutlu MF, Api M, Çetin A. The effects of pregnancy on the sexual life of Turkish women. Proc Obstet Gynecol. 2014;4(1):Article 5 [11 p.]. Available from: http://ir.uiowa.edu/pog/ Free full text article.

Corresponding author: Murat Bozkurt, Assistant Professor, Kafkas Üniversity Kampüsü Sağlık Araştırma ve Uygulama Hastanesi KARS/Turkey. Tel: 905322279072, 905056330044. Fax: 047422514 30. E-Mail: indrmb@yahoo.com

Financial Disclosure: The authors report no conflict of interest.

Copyright: (C) 2014 Bozkurt et al. This is an open-access article distributed under the terms of the Creative Commons Attribution License, which permits unrestricted use, distribution, and reproduction in any medium, provided the original author and source are credited. 
In the current literature, sexual function in pregnancy has been the subject of many studies. Numerous studies have shown that pregnancy has a negative effect on sexual function. ${ }^{2-10}$ However; the data about female sexual function is limited due to a lack of validated instruments and the retrospective design of studies. Different social, cultural and religious beliefs may influence the sexuality of couples in pregnancy.

Especially in societies with conservative traditional norms that are strongly influenced by religious beliefs and socio-economic inequality, sexuality cannot be discussed in an open and comprehensive manner. Even healthcare providers refrain from extensive discussion and sufficient counseling is usually not given; consequently, superstitions, misguided beliefs and behaviors are prevalent. Pregnancy is a period when several physical, hormonal and psychological changes take place simultaneously. Quality of life suffers seriously as a result of misguided counseling and false beliefs in societies where the detrimental effects of this period on sexuality cannot be discussed freely; therefore, we have decided to investigate the effects of pregnancy on the sex life of pregnant Turkish women. This is one of the largest studies about this issue in the English literature.

\section{Materials and Methods}

A total of 1026 pregnant Turkish women, who were admitted to The Ministry of Health Haseki Training and Research Hospital Antenatal Clinic of Obstetrics and Gynecology, were included in the study. The approval of the ethics committee was obtained prior to the study. After an information session consisting of a detailed explanation of the study, those women agreeing to take participate in the study gave informed consent.

\section{$\underline{\text { Inclusion criteria }}$}

Inclusion criteria included being pregnant, ability to read and write Turkish, and being in a stable relationship with a male partner.

\section{Exclusion criteria}

To eliminate the possible effects on sexual function, patients with systemic diseases (diabetes, thyroid dysfunction, heart disease), a sexual partner living separately, a history of drug use, and a diagnosis of psychiatric disorders were excluded from the study.

\section{Questionnaire}

The questionnaires were completed by the participants. Pregnant women were asked to mark an option that best fits her sexual life during pre-pregnancy and pregnancy periods. The patient's age, gestational age, weight and height values were recorded. The number of previous pregnancies, parity, abortion, cesarean sections, curettage and the presence of dyspareunia were also recorded. The patients were asked four questions in the self-completed questionnaire:

1. How often do you have sex or masturbate?

2. Do you masturbate?

3. Who starts the sexual activity? (Who asks for or implies sex first)

4. Do you achieve orgasm by yourself and/or with your partner? 
Depending on the answers to the questions, libido scores were assigned on a twelve point scale, by one physician (Table 1). Developed in 1997 by Api et. al., the Libido Scoring System (LSS) includes questions on four domains: orgasmic function, coital frequency, sexual desire, and masturbation (Table 1 ). ${ }^{11}$ The patients were scored according to Table 1 and a total score less than 3 was considered as loss of libido; scores of 3 and 4 were considered as low libido, 5-7 as moderate libido, and 8-12 as high libido. The total score of all the questions from LSS states patient's libido score. The libido scores were calculated for each patient for pre- pregnancy and pregnancy periods and compared.

\section{Statistical Analysis}

The data was analyzed by using the Statistical Package for Social Sciences software 15.0 for Windows package software (SPSS Inc, Chicago, Illinois, USA). $\quad \mathrm{P}<0.05$ was considered statistically significant. Categorical data were expressed by percentage and comparisons were made by the $\mathrm{x} 2$ test. Continuous variables were expressed as mean and standard deviation if normally distributed and compared by Student's t test or analysis of variance.

\section{Table 1. Libido Scoring System}

\begin{tabular}{|c|c|c|c|c|}
\hline Item/Score & $\mathbf{0}$ & 1 & 2 & 3 \\
\hline $\begin{array}{l}\text { Intercourse } \\
\text { frequency }\end{array}$ & None & $\leq$ Once a week & Twice a week & >Twice a week \\
\hline Masturbation & Does not & & & Does \\
\hline $\begin{array}{l}\text { Who starts sexual } \\
\text { activity }\end{array}$ & Always partner & Mostly partner & Mostly herself & Always herself \\
\hline Orgasm & Never & Sometimes & Frequently & Always \\
\hline
\end{tabular}

0-2 scores: loss of libido. 3-4 scores: low libido. 5-7 scores: good libido. 8-12 scores: high libido.

\section{Results}

The mean age, the mean weight, the mean height, the mean body mass index (BMI) value, the mean gravida, the mean parity, the average number of abortions, the average number of cesarean section, the average number of curettage, the average number of children and the average gestational age were recorded (Table 2). $25.5 \%$ of all pregnant women (262/1026) were in the first trimester, $43.9 \%$ (450/1026) were in the second trimester, and $30.6 \%(314 / 1026)$ were in the third trimester.
Table 2. Demographics

\begin{tabular}{ll}
\hline Age (years) & $\mathbf{2 6 . 0} \pm \mathbf{5 . 2 8}$ \\
\hline Weight (kg) & $65.0 \pm 11.4$ \\
\hline Height (meter) & $1.60 \pm 0.06$ \\
\hline BMI (kg/m2) & $25.0 \pm 4.24$ \\
\hline Gravida (n) & $2.30 \pm 1.67$ \\
\hline Parity (n) & $1.04 \pm 1.25$ \\
\hline Abortion (n) & $0.22 \pm 0.56$ \\
\hline Cesarean (n) & $0.23 \pm 0.50$ \\
\hline Living birth (n) & $0.98 \pm 1.15$ \\
\hline Gestational week & $22.0 \pm 10.04$ \\
\hline
\end{tabular}


Table 3. Comparison of intercourse frequency, masturbation rates, intercourse initiation, and orgasm rates between pregnancy and pre-pregnancy period.

\begin{tabular}{|llll|}
\hline & Pregnancy (n, \%) & Pre-pregnancy (n, \%) & $\boldsymbol{p}$ \\
\hline Intercourse frequency & & & $<0.01$ \\
\hline None & $59(5.8)$ & $4(0.4)$ & $<0.01$ \\
\hline$\leq$ Once a week & $578(56.3)$ & $218(21.3)$ & $<0.01$ \\
\hline Twice a week & $307(29.9)$ & $506(49.4)$ & $<0.01$ \\
\hline$>$ Twice a week & $82(8)$ & $298(29)$ & $<0.05$ \\
\hline Masturbation & & & $<0.05$ \\
\hline Does not & $931(90.7)$ & $977(95.2)$ & $\mathrm{NS}$ \\
\hline Does & $47(3.6)$ & $37(4.6)$ & $\mathrm{NS}$ \\
\hline Intercourse initiation & & & $\mathrm{NS}$ \\
\hline Always partner & $318(31)$ & $306(29.8)$ & $\mathrm{NS}$ \\
\hline Mostly partner & $586(57.1)$ & $664(64.7)$ & $<0.05$ \\
\hline Mostly herself & $64(6.2)$ & $50(4.9)$ & $<0.05$ \\
\hline Always herself & $0(0)$ & $4(0.4)$ & $<0.05$ \\
\hline Orgasm & & & $<0.05$ \\
\hline Never & $111(10.8)$ & $223(21.7)$ & $497(48.4)$ \\
\hline Sometimes & $515(50.2)$ & $148(14.4)$ & $100(9.7)$ \\
\hline Frequently & $251(24.5)$ & & \\
\hline Always & $147(14.3)$ & & \\
\hline
\end{tabular}

NS; Not significant

Zero point four percent (4/1026) of the cases never had sexual intercourse at all in the pre-pregnancy period; while during pregnancy, $5.8 \%(59 / 1026)$ of patients had no sexual intercourse. The percentages of patients having sexual intercourse twice a week or more were $78.3 \%(804 / 1026)$ in the pre-pregnancy period and $37.9 \%$ (389/1026) during pregnancy (Table 3). The difference is statistically significant $(p<0.05)$. The average frequencies of sexual intercourse were higher in the pre- pregnancy period in comparison to the pregnancy period (3.07/ week vs $2.40 /$ week; $p<0.001$ ). When grouped by trimester, a decrease in the frequency of sexual intercourse was observed as the trimesters progressed.

The masturbation rate in the prepregnancy period was $4.6 \%$ (47/1024), whereas during pregnancy it was $3.6 \%$
(37/968) (Table 3). The frequency of masturbation during pregnancy was found to be statistically lower than during the pre-pregnancy period ( $p$ $<0.05$ ). Masturbation rates, according to trimesters were $3.6 \%$ in the 1 st trimester, $3.5 \%$ in the 2nd trimester and $3.3 \%$ in the 3rd trimester. There was not a statistically significant difference in the masturbation rates, according to trimesters $(p>0.05)$. The masturbation rate for the prepregnancy period was statistically higher compared to pregnancy $(p<0.05)$.

Five point seven percent of the participants did not answer the question 'Who initiates sexual intercourse during pregnancy'. Sexual intercourse is mostly initiated by men, both in pre-pregnancy and pregnancy periods. The rates of initiation of sexual 
intercourse in the pre-pregnancy period by men and by women were 94.5\% (970/1026) and 5.3\% (54/1026) respectively. During pregnancy, these rates were 93.4\% (904/968) and 6.6\% (64/968) respectively (Table 3 ). There were no statistically significant differences in the rate of initiation of sexual intercourse either between prepregnancy, trimesters or during pregnancy $(p>0.05)$.

Five point seven percent of the patients participating in our study in pre-pregnancy period and $0.2 \%$ participants in pregnancy period did not respond to questions about orgasm. The percentage of pregnant women who had never had an orgasm, had an orgasm (occasional and often) and always had orgasm in every sexual intercourse during prepregnancy period was $10.8 \%$ (111/1026), $74.7 \%$ (766/1026), and $14.3 \%(147 / 1026)$ respectively. The percentage of pregnant women who had never had an orgasm, had an orgasm (occasional and often) and always had an orgasm every sexual intercourse in pregnancy period was 23.0\% (223/968), 66.6\% (645/968), and $10.3 \% \quad(100 / 968)$ respectively (Table 3 ). In responders, a statistically significant difference was found between the frequency of orgasm during pregnancy and pre-pregnancy $(p<0.05)$. The percentages of pregnant women who had never had an orgasm in the first trimester, the second trimester and the third trimester were $25 \%, 18 \%$, and $28 \%$ respectively. Trimester comparison showed that orgasms were statistically increased in the second trimester $\quad(p<0.05)$; however, orgasms were significantly decreased in all trimesters compared to the pre-pregnancy period $(p<0.05)$.
Table 4. Libido scores in pregnancy and pre-pregnancy periods

\begin{tabular}{lll}
\hline $\begin{array}{l}\text { Libido } \\
\text { Score }\end{array}$ & $\begin{array}{l}\text { Pregnancy } \\
(\mathrm{n}, \%)\end{array}$ & $\begin{array}{l}\text { Pre-pregnancy } \\
(\mathrm{n}, \%)\end{array}$ \\
\hline 4 & $68(6.6)$ & $15(1.5)$ \\
5 & $181(17.6)$ & $90(8.8)$ \\
6 & $289(28.2)$ & $197(19.2)$ \\
7 & $248(24.2)$ & $275(26.8)$ \\
8 & $118(11.5)$ & $235(22.9)$ \\
9 & $46(4.5)$ & $148(14.4)$ \\
10 & $17(1.7)$ & $58(5.7)$ \\
11 & $10(0.1)$ & $4(0.4)$ \\
12 & $0(0)$ & $2(0.2)$ \\
\hline
\end{tabular}

In our study, the libido score was assessed on a 12 point scale. Patients with a libido score $\leq 5$ were classified as a low libido category. The average libido score in pre-pregnancy period was $7.31 \pm 0.04$, and the libido score of pregnant women was 6 and higher was $89.7 \%$ (919/1024). The average libido score in pregnancy was $6.38 \pm 0.04$, while the rate of pregnant women with a libido score of 6 and higher was $74.3 \%$ of $(719 / 968)$ (Table 4). The average libido score during pregnancy was statistically lower than during the pre-pregnancy period $(p<0.05)$. The percentage of women categorized as having a low libido was statistically higher during pregnancy $(p<0.001)$. Libido scores were calculated for different trimesters and they were $6.45 \pm 1.31,6.49 \pm 1.34$, and 6.18 \pm 1.33 , respectively. The first trimester and second trimester libido scores were not statistically different $(p>0.05)$. Third trimester libido scores were lower than the first and second trimester scores. These differences between the first and third trimester, and between the second and third trimester were statistically significant $(p<0.05)$. The mean libido score in the pre-pregnancy period was compared to libido scores in each trimester; and all trimester's libido scores were found to be decreased. 


\section{Discussion}

Emotional and physical changes during pregnancy influence sexual functioning during gestation. Although $90 \%$ of pregnant women are sexually active during pregnancy, as the pregnancy continues, sexual activity decreases and reaches one third in the last month of pregnancy. ${ }^{12}$ The present study revealed that pregnancy has a negative effect on sexuality in terms of sexual frequency, masturbation rates, and orgasm frequency. The negative effect of pregnancy on sexual functions has been attributed to various factors such as physical discomfort, fear of fetal injury, decreased libido, and altered self-image. ${ }^{4,6,12,13}$

In the current literature, many studies show that pregnancy has a negative effect on sexual function. ${ }^{1,7,8,13-19}$ In a meta-analysis of 59 studies investigating sexuality during pregnancy and the postpartum period, it was shown that the frequency of sexual intercourse compared to the prepregnancy period was slightly decreased or remained unchanged in the first trimester, variable in the second trimester, and suddenly decreased in the third trimester. ${ }^{12}$ However, in some studies, it was reported that pregnancy has no effect on sexual function. ${ }^{7}$ Naim and Bhutto's study, including 150 pregnant women, showed that the frequency of sexual intercourse was 1.6 times per week during pregnancy, and 3.5 times per week pre-pregnancy. ${ }^{1}$ Similar results were obtained in our study with the frequencies of sexual intercourse during pregnancy and pre-pregnancy period being 2.4 times per week and 3.04 times per week respectively. One of the main reasons for the decreased coital frequencies is the belief that vaginal intercourse during pregnancy may cause miscarriage, premature labor, or fetal damage. In the study by Bartellas et al., it was demonstrated that $49 \%$ of women were worried about the harmful effects of sexual intercourse during pregnancy. ${ }^{4}$ However, there is no evidence of any harmful effects of sexual intercourse on pregnancy outcome in the current literature. The studies investigating the role of coitus on preterm delivery revealed that sexual activity does not cause preterm labor. ${ }^{20,21}$

Social, cultural, and/or religious factors may also impact sexual behavior during pregnancy. Two important characteristics of our study population were their lower socioeconomic status and strongly held conservative religious beliefs. In a study conducted in an Iranian population, masturbation was reported in $6 \%$ of pregnant women. ${ }^{22}$ Whereas in a Portuguese population, the masturbation rate was $20.4 \%{ }^{2} \quad$ Among Nigerian pregnant women, sexual intercourse during pregnancy was thought to facilitate labor by widening the vagina in $44.3 \%$, to improve fetal well-being in $34.8 \%$ and to cause an early miscarriage in $30.2 \%{ }^{23}$ In contrast to this, in a study conducted in Iran, pregnant women reported fear of rupture of the hymen of the female fetus or fetal blindness. ${ }^{22}$ In another study, more than $80 \%$ of Chinese couples were worried about the adverse effects of sexual activity on the fetus during pregnancy. ${ }^{24}$

In the present study, sexual frequency and libido scores were found to decrease as the gestation progressed. The libido score measurement as an indirect measure of sexual function, revealed that sexual function in the third trimester was significantly depressed compared to the first and second trimesters. This correlates well 
with the current literature..$^{2-6,8,12,15,25} \mathrm{~A}$ recent review, including 48 articles, reported that sexual function declined in pregnancy especially in the third trimester. $^{26}$ The deep engagement of the fetal head, stress incontinence, hemorrhoids, weight of the partner on the uterus during sexual intercourse, and subluxation of the pubic symphysis and sacroiliac joints are possible mechanisms of decreased sexual function in the third trimester compared with early pregnancy. ${ }^{36}$ Endocrine changes during pregnancy might be another possible mechanism leading to a decrease in sexual function. Although there is an increase in all sex hormones during pregnancy, no correlation was observed between sexual function and hormone levels. $^{3,5,27}$

Studies examining orgasm in pregnancy revealed lower orgasm rates during pregnancy compared to pre-pregnancy. ${ }^{28}$ Female Orgasmic Disorder, the second most frequently reported sexual problem is considered to be the persistent or recurrent delay in, or absence of, orgasm following a normal sexual excitement phase that causes marked distress or interpersonal difficulty (DSM-IV). ${ }^{29}$ In a study conducted in Hong Kong, it was shown that frequency of orgasm and enjoyment of intercourse also decreased with advancing gestation. ${ }^{30}$ We determined that sexual satisfaction does not change during pregnancy compared with the pre-pregnancy patterns despite a decline of sexual activity during the third trimester. Younger women were more likely to have sex and an orgasm during the first trimester; however, no consistent correlation was found either before or during pregnancy for sexual behavior, age, parity, employment status or level of education. ${ }^{30}$ In the present study, the percentage of pregnant women who had never had an orgasm, had an orgasm (occasional and often) and always had an orgasm every sexual intercourse in the pre-pregnancy period was $10.8 \%, 74.7 \%$, and $14.3 \%$, respectively. The percentage of pregnant women who had never had an orgasm, had an orgasm (occasional and often) and always had an orgasm every sexual intercourse in the pregnancy period was $21.7 \%, 62.8 \%$, and $9.7 \%$ respectively. A significant decrease in the frequency of orgasm in pregnancy period compared with the pre-pregnancy period was detected. Some possible explanations for this include nausea, vomiting, fatigue, dyspareunia, lethargy and uterine enlargement during pregnancy as well as an overwhelming concern for the fetus.

Most of the couples who had non-coital sexual behaviors before pregnancy (masturbation, orogenital sex, etc.) abandoned most of these activities during pregnancy. In a study conducted among Nigerian women, masturbation and anal intercourse increased, while oral sex decreased during pregnancy. $^{31}$ A study, investigating sexual perceptions during pregnancy from Portugal, reported a masturbation rate of $20.4 \%$ and reached the conclusion that despite a decline in sexual activity, pregnancy does not have an effect on sexual satisfaction. $^{2}$ In our study, the frequency of masturbation during pregnancy was significantly decreased, while the masturbation rate in the prepregnancy period was $4.6 \%$, it was $3.8 \%$ during pregnancy. Many studies reported that pregnancy may lead to decreased sexual desire. ${ }^{9,28}$ Solberg et al., interviewed 260 women and found that coital activity, sexual interest and non-coital sexual behaviors were 
decreased throughout pregnancy. ${ }^{9}$ In our study, the Libido Scoring System(LSS) was used; while the average value in the pre-pregnancy period was 7.31 , this was decreased to 6.38 during pregnancy. The libido scores were 6.45 in the first trimester, 6.49 in the second trimester, and 6.18 in the third trimester. The third trimester libido score was lower than the first and second trimester libido scores. Differences between the first and the third trimester, as well as between the second and the third trimester were statistically significant. There was a slight tendency for an increase in sexual desire in the second trimester. There was a decrease in sexual desire in the third trimester with some possible reasons being a limitation of movement due to an enlarged uterus in the third trimester, fear of impending labor, and pain due to pelvic compression, as well as the fear of losing or causing harm to the fetus.

In the present study, the Libido Scoring System which is a simple questionnaire involving four questions was used. Patients were more comfortable with the questionnaires than with in person interviews. ${ }^{32}$ In the current literature, questionnaires such as the Female Sexual Function Index and the McCoy Female Sexual Function Questionnaire are used to evaluate sexual function in pregnancy. ${ }^{33,34}$ The Female Sexual Function Index (FSFI) was wellcorrelated with the LSS, revealing a correlation coefficient of $0.96(p<0.001)$ (Cronbach $\alpha$ coefficient was found to be 0.83 and the kappa values of total scores were 0.67 and 0.77$).{ }^{11}$ The ease of LSS seems to be an advantage whereas validation of the test in a limited number of studies seems to be a limitation of our study. ${ }^{11,35}$

\section{Conclusion}

Our study demonstrates that pregnancy seems to have a negative effect on female sexuality in terms of coital frequency, achieving orgasm and masturbation rates in Turkish couples, but more prospective studies are required to further clarify the mechanisms.

\section{References}

1. Hogan RM. Human sexuality: a nursing perspective. New York: Appleton- Century- Crofts. 1980. p. 469-84.

2. Pauleta JR, Pereira NM, Graça LM. Sexuality during pregnancy. J Sex Med. 2010 Jan;7(1 Pt 1):136-42. doi: 10.1111/j.1743-6109.2009.01538.x.

Epub 2009 Oct 20. PubMed PMID: 19845548.

3. Aslan G, Aslan D, Kizilyar A, Ispahi C, Esen A. A prospective analysis of sexual functions during pregnancy. Int J Impot Res. 2005 Mar-Apr;17(2):1547.

http://dx.doi.org/10.1038/sj.ijir.3901288 . PubMed PMID: 15538394.

4. Bartellas E, Crane JM, Daley M, Bennett KA, Hutchens D. Sexuality and sexual activity in pregnancy. BJOG. $2000 \quad$ Aug;107(8):964-8. http://dx.doi.org/10.1111/j.14710528.2000.tb10397.x. PubMed PMID: 10955426

5. Erol B, Sanli O, Korkmaz D, Seyhan A, Akman T, Kadioglu A. A crosssectional study of female sexual function and dysfunction during pregnancy. J Sex Med. 2007 Sep;4(5):1381-7

http://dx.doi.org/10.1111/j.17436109.2007.00559.x. Epub 2007 Jul 25. PubMed PMID: 17651387. 
6. Pauls RN, Occhino JA, Dryfhout VL. Effects of pregnancy on female sexual function and body image: a prospective study. J Sex Med. 2008 Aug;5(8):1915-22. doi: 10.1111/j.17436109.2008.00884.x. Epub 2008 Jun 10. PubMed PMID: 18547388.

7. Connolly A, Thorp J, Pahel L. Effects of pregnancy and childbirth on postpartum sexual function: a longitudinal prospective study. Int Urogynecol J Pelvic Floor Dysfunct. $2005 \quad$ Jul-Aug;16(4):263-7. http://dx.doi.org/10.1007/s00192-0051293-6. Epub 2005 Apr 19. PubMed PMID: 15838587.

8. Leite AP, Campos AA, Dias AR, Amed AM, De Souza E, Camano L. Prevalence of sexual dysfunction during pregnancy. Rev Assoc Med Bras. 2009 Sep-Oct;55(5):563-8. http://dx.doi.org/10.1590/S010442302009000500020. PubMed PMID: 19918657.

9. Bogren LY. Changes in sexuality in women and men during pregnancy. Arch Sex Behav. 1991 Feb;20(1):3545.

http://dx.doi.org/10.1007/BF01543006. PubMed PMID: 2003770.

10. Corbacioglu Esmer A, Akca A, Akbayir O, Goksedef BP, Bakir VL. Female sexual function and associated factors during pregnancy. J Obstet Gynaecol Res. 2013 Jun;39(6):1165-72. doi: 10.1111/jog.12048. Epub 2013 May 30. PubMed PMID: 23718891.

11. Api M, Api O, Görgen H, Cetin A, Yayla A. New diagnostic instrument for sexual function assessment in menopausal women: Libido Scoring System. J Turkısh German Gynecol Assoc. 2005; 6(1): 24-29.

12. von Sydow K. Sexuality during pregnancy and after childbirth: a metacontent analysis of 59 studies. J Psychosom Res. 1999 Jul;47(1):27-49. http://dx.doi.org/10.1016/S00223999(98)00106-8. PubMed PMID: 10511419.
13. Trutnovsky G, Haas J, Lang U, Petru E. Women's perception of sexuality during pregnancy and after birth. Aust N Z J Obstet Gynaecol. 2006 Aug;46(4):282-7. http://dx.doi.org/10.1111/j.1479828X.2006.00592.x. PubMed PMID: 16866787.

14. Brtnicka $H$, Weiss $P$, Zverina J. Human sexuality during pregnancy and the postpartum period. Bratisl Lek Listy. 2009;110(7):427-31. PubMed PMID: 19711831.

15. Jamali S, Mosalanejad L. Sexual dysfnction in Iranian pregnant women. Iran J Reprod Med. 2013 Jun;11(6):479-86. PubMed PMID: 24639782; PubMed Central PMCID: PMC3941320.

16. Eryilmaz G, Ege E, Zincir H. Factors affecting sexual life during pregnancy in eastern Turkey. Gynecol Obstet Invest. 2004;57(2):103-8. http://dx.doi.org/10.1159/000075582.

Epub 2003 Dec 15. PubMed PMID: 14673220.

17. Johnson CE. Sexual health during pregnancy and the postpartum. J Sex Med. 2011 May;8(5):1267-84; quiz 1285-6. doi: 10.1111/j.17436109.2011.02223.x.PubMed PMID: 21521481.

18. Prado DS, Lima RV, de Lima LM. [Impact of pregnancy on female sexual function]. Rev Bras Ginecol Obstet. 2013 May;35(5):205-9. http://dx.doi.org/10.1590/S010072032013000500003. PubMed PMID: 23843117.

19. Ahmed MR, Madny EH, Sayed Ahmed WA. Prevalence of female sexual dysfunction during pregnancy among Egyptian women. J Obstet Gynaecol Res. 2014 Apr;40(4):1023-9. doi: 10.1111/jog.12313. Epub 2014 Mar 10. PubMed PMID: 24612115. 
20. Sayle AE, Savitz DA, Thorp JM Jr, Hertz-Picciotto I, Wilcox AJ. Sexual activity during late pregnancy and risk of preterm delivery. Obstet Gynecol. $2001 \quad$ Feb;97(2):283-9. http://dx.doi.org/10.1016/S00297844(00)01147-9. PubMed PMID: 11165596.

21. Kurki T, Ylikorkala O. Coitus during pregnancy is not related to bacterial vaginosis or preterm birth. Am J Obstet Gynecol. 1993 Nov;169(5):1130-4. http://dx.doi.org/10.1016/00029378(93)90268-N. PubMed PMID: 8238172.

22. Shojaa M, Jouybari L, Sanagoo A. The sexual activity during pregnancy among a group of Iranian women. Arch Gynecol Obstet. 2009 Mar;279(3):353-6. doi: 10.1007/s00404-008-0735-z. Epub 2008 Jul 30. PubMed PMID: 18665379.

23. Adinma JI. Sexuality in Nigerian pregnant women: perceptions and practice. Aust N Z J Obstet Gynaecol. 1995 Aug;35(3):290-3. http://dx.doi.org/10.1111/j.1479828X.1995.tb01984.x PubMed PMID: 8546646.

24. Fok WY, Chan LY, Yuen PM. Sexual behavior and activity in Chinese pregnant women. Acta Obstet Gynecol Scand. 2005 Oct;84(10):934-8. http://dx.doi.org/10.1080/j.00016349.2005.00743.x PubMed PMID: 16167907.

25. Erenel AS, Eroglu K, Vural G, Dilbaz B. A pilot study: In what ways do women in Turkey experience a change in their sexuality during pregnancy? Sexuality and Disability. 2011 Sept;29(3):207- 216. http://dx.doi.org/10.1007/s11195-0119200-1
26. Serati M, Salvatore S, Siesto G, Cattoni E, Zanirato M, Khullar V, Cromi A, Ghezzi F, Bolis P. Female sexual function during pregnancy and after childbirth. J Sex Med. 2010 Aug;7(8):2782-90. doi: 10.1111/j.17436109.2010.01893.x. Epub 2010 Jul 7. PubMed PMID: 20626601.

27. Stuckey BG. Female sexual function and dysfunction in the reproductive years: the influence of endogenous and exogenous sex hormones. J Sex Med. 2008 Oct;5(10):2282-90. doi: 10.1111/j.1743-6109.2008.00992.x. PubMed PMID:19007404.

28. Oruç $S$, Esen $A$, Laçin $S$, Adigüzel $H$, Uyar Y, Koyuncu F. Sexual behavior during pregnancy. Aust N Z J Obstet Gynaecol. 1999 Feb;39(1):48-50. http://dx.doi.org/10.1111/j.1479828X.1999.tb03443.x. PubMed PMID: 10099749.

29. Meston CM, Hull E, Levin RJ, Sipski M. Disorders of orgasm in women. J Sex Med. 2004 Jul;1(1):66-8. DOI: 10.1111/j.1743-6109.2004.10110.x. PubMed PMID: 16422985.

30. Haines CJ, Shan YO, Kuen CL, Leung $\mathrm{DH}$, Chung TK, Chin R. Sexual behavior in pregnancy among Hong Kong Chinese women. J Psychosom Res. $1996 \quad$ Mar;40(3):299-304. http://dx.doi.org/10.1016/00223999(95)00644-3. PubMed PMID: 8861126.

31. Bello FA, Olayemi O, Aimakhu CO, Adekunle AO. Effect of pregnancy and childbirth on sexuality of women in ibadan, Nigeria. ISRN Obstet Gynecol. 2011;2011:856586. doi: 10.5402/2011/856586. Epub 2010 Oct 5.

http://dx.doi.org/10.5402/2011/856586. PubMed PMID:21647230.

32. Rosen RC. Assessment of female sexual dysfunction: review of validated methods. Fertil Steril. 2002 Apr;77 Suppl 4:S89-93. DOI: 10.1016/S00150282(02)02966-7. PubMed PMID: 12007910. 
33. Rosen R, Brown C, Heiman J, Leiblum S, Meston C, Shabsigh R, Ferguson D, D'Agostino R Jr. The Female Sexual Function Index (FSFI): a multidimensional self-report instrument for the assessment of female sexual function. J Sex Marital Ther. 2000 AprJun;26(2):191-208.

http://dx.doi.org/10.1080/00926230027

8597. PubMed PMID: 10782451.

34. McCoy NL. The McCoy female sexuality questionnaire. Qual Life Res 2000;9(1 Suppl): $\quad 739-745$. http://dx.doi.org/10.1023/A:100892590 6947.

35. Narin R, Nazik H, Narin MA, Aytan H, Api M. An evaluation of the effects of the transobturator tape procedure on sexual satisfaction in women with stress urinary incontinence using the libido scoring system. ISRN Obstet Gynecol. 2013 Oct 28;2013:627671. doi: 10.1155/2013/627671. eCollection 2013. PubMed PMID:24288621. 